\title{
E-PLANNER FOR PHYSICAL EDUCATION ON THE SECONDARY SCHOOL LEVEL IN LATVIA
}

\author{
Arturs Pilkevics ${ }^{1}$, Rasma Jansone ${ }^{2}$, Inese Bautre ${ }^{3}$
}

\author{
${ }^{1}$ Surabaya Intercultural School \\ Address: Teacher Housing C-2, Lakarsantri, Citraland, Surabaya 60225, Indonesia \\ Phone: +628113322707 \\ E-mail: a.pilkevics@gmail.com \\ ${ }^{2}$ Latvian Academy of Sport Education \\ Address: 333 Brivibas Street, Riga, LV - 1006, Latvia \\ Phone: + 37167543430 \\ E-mail: rasma.jansone@1spa.lv \\ ${ }^{3}$ National Centre for Education \\ Address: 2 Vaḷnu Street, 2, Riga LV-1050, Latvia \\ Phone: +37167216500 \\ E-mail: inese.bautre@,visc.gov.lv
}

\begin{abstract}
An innovative planning and assessment tool for the subject of Physical Education (PE) on the secondary school level has been created in the course of this research project. Evaluation of the research on the Latvian assessment system in $P E$ has shown the current need for an online based curriculum planning tool (eplanner) which would help teachers to effectively and qualitatively determine the levels of knowledge, skills, personal trait attributes and development dynamics in PE. This finding has served as basis for the hypothesis of the work: creating an eplanner will have a positive influence on the planning and evaluation processes in the subject of Physical Education on secondary level. The author set put to determine the theoretical foundation and the desired content of the E-planner according to the curriculum standard of PE on the secondary level in Latvia and create the planner based on the free Google Forms online platform. Study included the evaluation of teachers' opinion about using the E-planner for planning and evaluation purposes. The result of this project is the first on-line curriculum planning tool in the Latvian language which is based on the modern theoretical understanding of student-centered planning and the assessment approach in education. Implementing such a tool on a state level across the disciplines would improve the quality of planning and instruction in schools.
\end{abstract}

Key words: Curriculum Planning, Physical Education 


\section{Introduction}

The historical investigation tracing the evolution of planning and evaluation in education has shown several common tendencies indicating the general paradigm shift from normative assessment to criteria-based assessment with corresponding changes in planning techniques and curriculum content development. The psychometric testing era of the early 20 th century was challenged by research on the effect of assessment on learning which started as early as 1960s (Glaser, 1963). Growing challenges of the ever faster changing world, along with the unpredictably progressive technological advancement challenged the notion of standardization of skills and knowledge, and increased the interest in finding the key to effective education. In evaluation and planning a new theory of qualitative assessment has emerged - studies in the 1980s and 1990s demonstrated the positive influence of feedback-driven, criteria-measured assessment on learning outcomes and results. This meant rethinking the value of exams, tests, and all summative evaluation in the learning process - admitting that in measuring the effectiveness of the learning process, the predominant value belongs to formative rather than summative assessment. These research findings were followed by a series of other studies in the late 1990s (e.g., Black et al.) which demonstrated the conservative character of education industry - the new understanding of assessment was there, but teachers were reluctant to implement change because it required additional effort and solid example of best practice in implementing the new paradigm. Examples of tools and methods were suggested and tested by various researchers and practitioners. At this point assessment for learning and its implications for the cohesiveness of planning, evaluation and guideline setting processes are establishing themselves in the educational systems all over the world. Latvia is not an exception, but rather a vivid example of this paradigm shift. During the Soviet era, the distinctively normative character of assessment policy was especially vivid in the area of physical education. The very name of the Soviet Physical education program "Ready for Defence and Work" implicated the direct link to state ideology of standardization and connection of one's fitness to military readiness. The Physical Education program was not primarily focused to address the individual needs of a diverse body of children, young men and women, but to create and mold them into one predictable and effective standard worker or soldier. Thus, the role of the teacher in terms of assessment was mainly to measure and compare the achievement of students to a certain standard and the teaching process was aimed at improving numbers and figures to fit a certain framework. Since Latvia regained its independence in 1991, much 
work has been done to re-adjust the educational program to fit the modern understanding of effective organization and implementation of teaching and learning. The change from a norm-driven standard to learning outcomesdefined standard in PE has finally come in 2008. The new and current state standard for PE defines summative and formative assessment and outlines the general standards as well as learning outcomes in four distinct categories.

However, when investigating the tools and instruments provided for Latvian teachers to help them implement the change, the author found no system of collaborative sharing as well as a lack of technological support available in this field. Currently, the only tools provided for the implementation of the new standard are lecture type professional development courses, several publication containing examples of methods and approaches. Acknowledging this situation inspired the author to take action and create an innovative planning tool which would enable teachers to create and share unit plans in PE that would be aligned with the modern understanding of an effective educational planning, where state standards, unit plans and assessment are linked and mutually supportive.

\section{Material and Methods}

The goal of this project was to create a portal with a unit planning tool, using instructions for it, as well as unit sharing options. The portal would become a place for planning, collaboration, reflection and an effective resource at the same time.

After the general description of the unit in the first step, the planning tool has the State standards and corresponding learning outcomes pre-set and ready for choice in the second step. Teachers are prompted to create guiding questions for each of the learning outcomes they have chosen. This aligns with the modern understanding of learning through inquiry. In the third step, the teachers are asked to describe the assessment methods with certain framework and parameters of description that corresponds to the modern understanding of assessment for learning. There are options to check and choose from formative or/and summative assessment; options for the time when assessment occurs; there are two separate text boxes for descriptions of teacher's and students' actions, a box for a general description of the activity and an opportunity to attach a file if there is premade rubric or description. The planner gives an opportunity to create 5 assessment methods per unit. Finally, in the last 4th step, the teachers can describe different activities which will be used to teach and learn the chosen learning outcomes. After submission, the program creates a Google document - an editable document which is made on the basis of pre-set 
template with teacher-chosen input values displayed in the corresponding parts of the document. Thus, the first page displays the values of the general description, the name and length of the unit. The second page outlines the chosen standards, learning outcomes and corresponding questions of inquiry in a visually transparent and clear manner. Then, the chosen learning outcomes are placed in the pre-set evaluation rubric and serve as assessment criteria for this unit with grading scale and point translation provided.

Finally, the suggested activities are listed and teachers are able to fill out the pre-made individual lesson plan tables, outlining the sequence and timeline for each lesson. In addition, the teachers are asked permission to use their plan as an example and if permission is granted, the pdf version of the unit (without the lesson plans) is automatically posted on the portal and becomes available for viewing and download by other teachers. Go to: http://www.planotsportu.lv/. The platform for creating of this system was Google Sites, Google Docs and JotForm free tools. Basically, the e-planner is an advanced online form which pushes the input data to a Google Spreadsheet which in turn uses the added script to automatically create a Google Document using the placeholder feature and data merge feature. The same feature is used for data in the mirror spreadsheet, to create PDF files and then post them on the website again using the free script for posting folders in Google Sites.

\section{Results}

To test the functionality of the e-planner, the project has been integrated into the professional development courses for PE teachers that took place in Riga and Tukums in the end of March 2013. As a result 42 teachers were introduced to the basic idea of the project and then given an opportunity to try out the planning process using the portal www.planotsportu.lv. After reading the instructions, teachers worked on creating unit plans using the e-planner. After this experiment an on-line survey with rating scale and open ended questions was conducted among teachers and 28 of them gave their responses.

The teachers rated the visual design, logical structure and format of the e-planner extremely well - more than $85 \%$ of respondents gave 4 or 5 on the scale of 5 for this categories. Around $80 \%$ also agree to a great extent that the e-planner tool helps to understand and use the State standard (curriculum guidelines) in PE. Just slightly less agreement (70\% agree) that the E-planner and the created unit plans are fully applicable in every day teaching routine. More teachers responded as "I don't know" to the questions related to usability of the project and its product. The correlational 
study revealed that some teachers were not able to create a plan due to time limitations, technical problems or their error in filling the planner template. Thus, there is a high degree of correlation between the rating of the layout of the created plan and the usability of the assessment criteria. Teachers who rated the layout as well designed also give a high rating to the usability of the plan, and vice versa - those who marked "I do not know" to the first, also responded "I do not know" to the second. This in turn simply proves a logical point without seeing the final product, it is hard to judge on its usability in practice, and most importantly - the vast majority of those who have seen the final product "strongly agree" or "agree" that it is usable in practice.

\section{Discussion}

The created system is fully functional, but the author acknowledges that it is only a prototype to a more advanced and effective IT solution for this idea. The author hopes that provided prototype can be used for a creation of an online planning and collaboration tool for all subjects on a state level in Latvia. Moreover, the vision is to create a social environment on the planning portal offering teachers the capability to share, download and, most importantly, rate the unit plans, which would be powered by monthly awards for the best rated and most downloaded plan.

\section{Conclusions}

The research provided in the work provided a solid base for the design and content implications of the E-planner Tool which was then successfully created and proved to be fully functional by testing done during the teacher professional development courses. The feedback from teachers indicates the positive outcome of this study. The implementation of the E-planner will not consequently provide for development of exemplary units of work, but also valuable data will be gathered about the best practices and the degree of implementation of the state standard in real life. In any case, the major motivation for accomplishment of this project is the desire to help Latvian teachers to better understand, implement and develop an effective curriculum in PE.

\section{References}

1. Resnick L. (ed.), Knowing, Learning and Instruction. Essays in honour of R Glaser, New Jersey: Lawrence Erlbaum Associates, 1989.

2. Black P. Testing: Friend or Foe? Theory and Practice of Assessment and Testing, London: Falmer Press, 1998.

Submitted: June 29, 2013

Accepted: December 9, 2014 